where the prognosis is poor but uncertain (as in many spina bifida cases); The question of acts and omissions with respect to patients not selected for remedial treatment, and the dealing with parents and relatives in such cases; The areas covered by the Warnock Report. And there are questions connected with the quality of life and the criteria of personhood. In general there is a wise stress on professional integrity and codes of conduct rather than legal prescriptions.

The book is right up to date. There are many references to work in the last four years, and it even manages to include the recommendations of the Warnock Report. The text is clearly written; there are good and detailed references; appendices include the Nuremberg Code, the Declaration of Helsinki, and the Human Tissues Act of 1961. There is a glossary of medical terms used (oocytes is omitted), an index of persons and one of subjects; and questions for discussion on each chapter.

The author is chaplain of the University Hospital of Wales at Cardiff, and is one of the best known hospital chaplains in Britain. References to the Christian faith occur from time to time in an illustrative context, but the book is in no way a peculiarly Christian treatise on medical ethics. It provides the data needed for anyone to form responsible opinions provided they accept the necessity of knowing what is going on. Autton only occasionally indicates his own opinion. The technical details of each chapter have been checked by a medical expert in the field in question.

Things have been moving so rapidly in medical ethics in the last few years that Autton has rendered a valuable service; the art of haute vulgarisation is a valuable one and not all that common. This book is a fine example of it.

RONALD PRESTON Emeritus Professor of Social and Pastoral Theology, Manchester University

\section{Birth Defects: Clinical and Ethical Considerations}

Finley S C, Finley W H, Flowers Jr C E, eds. 240 pages, New York, March of Dimes, Birth Defects Foundation. Original Article Series Vol 19, number 15, Alan R Liss, 1983. £36.50.

The title of this book is partly misleading and partly correct. In fact, there is only a single chapter by an ethicist, John C
Fletcher, 'Ethics and Trends in Applied Human Genetics', which deals with genetical aspects and one other very shor article by R C Baumiller to do with ethics, 'Legal and Ethical Considerations'. This is a minimal contribution.

Fletcher's chapter, however, is very valuable and thoughtful and should usefully be read by everyone concerned with the management of defective newborn, whether the defect is structural or biochemical. It deals, with considerable medical knowledge, (he is not a medical person) about the already existing and possible future application of technology to prenatal treatment for the correction of deformities and disorders. Fletcher feels, I believe correctly, that moral and ethical considerations are not defined once and forever irrespective of social and technical changes in society and takes an intermediate view in this respect. He holds that morality interacts with technology and that social values of great import clearly influence the limits and possibilities of technology and that society itself is shaped and reshaped by their introduction.

JOHN LORBER

Emeritus Professor of Paediatrics, University of Sheffield,

Honorary Consultant Paediatrician, Sheffield Area Health Authority

\section{Brave New People}

Jones D G. 221 pages, Leicester £3.95, Inter-Varsity Press, 1984

There is little doubt that developments in biotechnology in recent years have revolutionised the approach to the management of genetic disease and infertility. But these developments have also generated many ethical problems, for the individual patient as well as the doctor. Much has already been written about these problems but often assuming some philosophical and scientific sophistication, thus limiting the appeal largely to a professional readership. And unfortunately the authors have occasionally not been scientists themselves and therefore accuracy has sometimes been sacrificed. But these criticisms cannot be levelled against this little book which is written by a professor of anatomy who writes in a simple, lively, straightforward style, which is both accurate and clear. He writes as a committed Christian and draws on biblical principles in attempting to resolve many of the problems. He is quick to point out, however, that there are no simple answers. Nevertheless, effort should be made to look beyond controversy and search for underlying principles and guidelines.

The first two chapters are concerned with the general philosophy of biotechnology which may be good at tackling disease but '.. is weak at promoting health in a positive way. It cannot take account of environmental, emotional, sociological and spiritual factors which together constitute the uniqueness of each person'. Subsequent chapters deal with major issues of current interest, including genetic screening, prenatal diagnosis (and therapeutic abortion), artificial insemination, in vitro fertilisation, and genetic engineering. The concluding chapter attempts to put these matters into perspective within the framework of the Christian ethic. The author argues that biotechnology must not be allowed to alter our goals and aspirations, otherwise we run the risk of making it a religion and an end in itself. Finally, there is a useful bibliography to the related scientific and ethical literature and a full index.

This is an eminently readable account of the major moral and ethical problems posed by recent developments in biotechnology, and it can be highly recommended to both scientists and non-scientists.

ALAN EMERY The Medical School Edinburgh

\section{Test Tube Conception}

Wood C, Westmore A. 134 pages, London, £4.95, George Allen \& Unwin, 1984

At $£ 4.95$, the cost of this book is a drop in the ocean compared with the cost of in vitro fertilisation (IVF) treatment to the average couple, and as such could be recommended to them without hesitation. Anything which prepares these couples for the considerable stress of their treatment and the likely probability of failure is to be endorsed. However, the book is also aimed at 'medical and counselling professionals' as well as those concerned with ethical, legal and social issues, and in this respect it is rather less satisfactory.

The book is written by Professor Carl Wood, who is head of the department in Melbourne out of which many of the major developments in IVF have come. 
His co-author is Ann Westmore, a medical journalist whose claim to fame is apparently a best-selling birth control book on The Billings Method. The book first tackles the process of conception and answers basic questions about infertility. Then there is a chapter about the development of the test-tube baby programme in Melbourne. The next few chapters describe the sort of patients who can be helped and go into the minutiae of the treatment and the stresses and practical problems, written very much with the patient in mind. For the few successful patients there is a reassuring chapter on the outcome of pregnancy, but this is put into perspective by a subsequent chapter on the limited current success of the procedure. Following this there is an ethical, social and religious justification of the procedure, written in the question and answer style. Although this chapter, on initial reading, comes across as rather complacent and glib, it has to be kept in mind that the book is aimed at neither the informed physician nor the moral philosopher. The final chapter on future prospects launches bravely into cloning and sperm microinjection as well as some of the other biological scenarios that have been perpetrated in Melbourne such as embryo donation, and makes rather too little of the less sensational, but more relevant advances in knowledge that can be achieved with continuing embryo research.

All in all, this is a book that has been written for the lay person rather than the professional, and I shall certainly be recommending it to my patients. Possibly I should have asked one of them to review it.

ALLAN TEMPLETON Department of Obstetrics and Gynaecology, University of Edinburgh

\section{A Guide to Symptom Relief in Advanced Cancer}

\author{
Regnard C F B, Davies A, Randall F. 44 \\ pages, Manchester, $£ 2.95$, Haigh and \\ Hochland, 1983.
}

The aim of this short book is to provide basic guidelines for the control of symptoms of patients dying of cancer. It is primarily concerned with therapeutics and ethical issues are not considered. Pain control dominates the first part. The common reasons for failure to control pain are considered: fear of analgesics, failure to diagnose, lack of pharmacological knowledge, poor use of adjuvant medication and inadequate reassessment. These common fears are allayed as the use of oral medication for pain control is discussed. The very limited need for injections is clearly stressed. Adjuvant medication to opiate analgesia is explained, but the relevant table appears too early in the chapter and anticonvulsants are not mentioned.

Diagnosis of the cause of the pain is not sufficiently emphasised. Correct treatment depends upon accurate diagnosis and most patients have several pains, each of which needs to be assessed. Some pains may be unrelated to the cancer and require different treatment.

A clear methodical approach of diagnosis leading to treatment is introduced when the control of nausea and vomiting is considered and there is a useful table of anti-emetic drugs. However, this approach is not always maintained with other symptoms and the need to diagnose is neglected in the enthusiasm to discuss treatment. Certain important and distressing symptoms, such as dyspnoea, are rather scantily covered. There is a very useful table of drug interactions and a full list of references.

However, the information is often lost in a complete jumble of headings and sub-headings, leaving the reader easily confused. Although this book could be helpful to many doctors, the presentation may in fact limit its usefulness.

D J OLIVER

Medical Director, The Wisdom Hospice, Rochester and Consultant Physician in Continuing Care to the Medway Health Authority

\section{Freud and Human Nature}

Dilman I. 207 pages, Oxford, £15, Blackwell, 1983

\section{Freud and the Mind}

Dilman I. 204 pages, Oxford, £15, Blackwell, 1983.

These clearly written and extensive investigations into the philosophical underpinnings of Freud's psychology are part of a larger research programme in which Dilman attempts a reconstruction, rather than an exegesis, of Freudian theory. Freud and Human Nature differs from most other studies on Freud in itso criticism of his hedonistic conception oft sexuality, of his account of the relationship between love and sexuality, ? and of his polarisation of human nature and culture and of instinct and morality It might be expected that when theseo theories have been removed there is littleo else of interest in Freud's programme. $\overline{\bar{p}}$. For Dilman, however, it is a necessary step towards seeing what is of lasting importance in Freud.

In the first two chapters of Freud and $\overrightarrow{0}$ Human Nature Dilman argues that even on Freud's terms a purely hedonistic $\vec{\omega}$ sexuality is really an infantile sexuality. $\stackrel{S}{S}$ Although the lifting of sexual repression $\overline{3}$ was important to Freud, it should not, $₫$ insists Dilman, be seen as either an $\vec{\overrightarrow{ }}$ advocacy of 'giving way to impulse' or as î a means of removing guilt in order to take $\vec{\circ}$ an easy way out of moral obligations. In the following chapters Dilman's critique $\delta$ is expanded into a reappraisal of Freud's 군 negativistic account of morality and his view of culture as an external restraint on $\subseteq$ instinct and human nature. In the course of his rejection of the quasi-mechanistic $\rightarrow$ polarities which dominate Freud's $\odot$ writings Dilman argues that Freud 8 s or only acceptable as a psychologist gif purged from his philosophigi presuppositions. But this raises mam problems than Dilman appears to recognise. It may be the case that bad philosophy distorts a scientific $\mathbb{Q}$ programme, but the remedy lies in its $\overrightarrow{\vec{A}}$ replacement with a better and more $\frac{O}{3}$ rigorous philosophical content. Yet $\mathcal{F}$ Dilman conveys the impression that it is the very contact with philosophy - rather than bad philosophy - which distorts Freud's psychology. Thus Freud? encounters 'certain philosophical 3 difficulties' and suffers from'philosophical confusions' whilst $\frac{O}{2}$ 'philosophical froth' and 'philosophical presuppositions' tend to 'get in the way'음 and 'distort his insight'. In this respect $>$ Dilman shares an assumption - 을 apparently held by Wittgenstein and Rhees - that the shedding of any o philosophical content is essential to N scientific progress. This kind of philosophic aversion therapy may be a $\mathrm{\omega}$ useful prophylactic against the wilder speculations of philosophers but it cane lead to a narrow and distortive $\bar{\varnothing}$ interpretation of the sciences and their? requirement for a sound appraisal of their $\bar{T}$ conceptual apparatus, which is

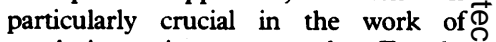
revolutionary innovators such as Freud. $\overrightarrow{\mathbb{D}}$

There is little doubt that Dilman has $\cong$ great respect for Freud and there is considerable value in this reconstruction 